\title{
Mucopolysaccharidosis type 3
}

INSERM

\section{Source}

INSERM. (1999). Orphanet: an online rare disease and orphan drug data base.

Mucopolysaccharidosis type 3. ORPHA:581

Mucopolysaccharidosis type III (MPS III) is a lysosomal storage disease belong ing to the group of mucopolysaccharidoses and characterised by severe and rapid intellectual deterioration. 